\title{
METAPHORIC TRANSFER OF KNOWLEDGE, CULTURAL EXPERIENCES AND SOCIAL PRACTICES IN ENGLISH LANGUAGE ADVERTISING DISCOURSE
}

\author{
Rumyana Todorova"
}

\begin{abstract}
The paper deals with metaphoric transfer of knowledge in English advertising discourse based on two- and cross-domain mappings referring to cultural conceptualisations of the world. On the one hand, text producers' awareness of social events, as well as of people's experiences and practices helps them in the construction of advertisements in the most intriguing and sensational way. On the other hand, text receivers are provoked and tempted by the ads deconstruction, though in some cases their unawareness of what is happening or has happened around us or in the world at large may block or hinder comprehension and thus lead to either misunderstanding of the message and their ignorance of it or to their complete indifference to it. The paper deals with all of the above mentioned issues supported by examples of English language ads and commercials. It shows in what ways multimodality related to the use of verbal and non-verbal signs works in them. The results prove the fact that the use of multimodal metaphors, especially in the non-verbal component, is supposed to trigger more emotions and feelings than the mere representation of the advertised items.
\end{abstract}

Key words: metaphoric transfer, multimodality, advertisements, domain mappings

\section{Introduction}

Advertising discourse performs social functions based on prior and background knowledge, familiar existing practices and cultural experiences about the world we live in. In this respect, text producers construct information with the help of metaphors so that it is as intriguing and sensational as possible for text receivers to be tempted by its deconstruction. The metaphoric transfer of knowledge is related to the use of two- and cross-domain mappings via different types of modal metaphors (in most cases multimodal) in both components of the text (verbal and non-verbal) and refers to cultural conceptualisations of the world target audiences should be familiar with. At the same time, our unawareness of what is happening or has happened around us or in the world at large may block or hinder comprehension and thus lead to either misunderstanding of the message and our ignorance of it or to our complete indifference to it. If the metaphors used cannot be comprehended, text receivers will either lose interest in the ad/commercial or neglect it completely which can even lead to a negative attitude towards the promoted item.

\footnotetext{
* Professor PhD at Shumen University, Department of English Studies, Shumen, Bulgaria, e-mail: r.todorova@shu.bg.
} 


\section{Previous research in the field}

There is extensive research on metaphors in linguistic contexts either from a traditional (see Molhova 1976; Downing, Locke 1992) or recently, from a cognitive perspective (see Lakoff, Johnson 1980; Goatly 2011; Donoghue 2014). However, these are just some of the studies and some of the issues raised as far as metaphor is concerned. Thus, for example, Lakoff and Johnson (1980) exploited one- and two-domain mappings as regards conceptual metaphors. Nowadays, the study of metaphor does not only remain within the confines of language, but it is also connected to our way of thinking, communication and culture (e.g. Emanatian 1995; Kövecses 2005). Musolff and Zinken (2009) discuss the role of discourse for metaphorical meaning and understanding in cases of constructing various social realities. Ideology is also considered to be of importance in cases in which metaphors are used (Goatly 2007). The issues are also expanded to the non-verbal representations of information which leads to the use of multimodal metaphors (see Forceville, Urios-Aparisi 2009; Kövecses 2010). Kövecses (2015) touches upon the role of context in metaphor. In a previous study, he combines feelings, emotions and culture in the use of metaphors (Kövecses 2000) and at a later stage (2009: 11-24) discusses the interrelation between metaphor, discourse and culture with an emphasis on the role of coherence. The relation between metaphors and social life is exploited by Schnall (2014).

Various researchers either call one and the same manifestations of metaphor in a different way or in some cases give them different interpretations. Thus, for example, Grady (2007) elaborates on the non-verbal occurrence of metaphors, while Fauconnier and Turner (2002) discuss their multimodality. Forceville (2006) and Rodríguez (2016) elaborate on these types of metaphors in advertising discourse, the former pointing out the differences between their use in print ads and commercials. One of the latest investigations is related to conceptual metaphor in social psychology and its workings in everyday life (see Landau 2017). On the other hand, Švažienè (2010) has done a depth-in research on the persuasive effects of different types of modal metaphors in the field of advertising.

\subsection{Research Questions}

The present case study is an attempt to combine the various treatments of metaphoric transfer in the verbal and non-verbal components of English language advertising texts taking into consideration text producers' and text receivers' previous and background knowledge about different social phenomena and practices exploited in these narratives, as well as knowledge about the world at large. Culture plays an important part in the construction and deconstruction process. The point of orientation is not disregarded either. 


\section{Methods}

The methods used for the analysis of advertisements is Critical Discourse Analysis (CDA) and cognitive linguistics approaches which help interpreting multimodal metaphoric transfer via two- and cross-domain mappings in both the verbal and the non-verbal components of the narratives. Various cultural factors and social practices are also taken into account if present and where needed.

\section{Data Analysis}

As the paper is part of a bigger study which focuses on the types of metaphoric transfer in commercials as well as in printed advertisements of different products, the analysis elaborates on the way some of these tools for presenting one domain with the help another are exploited.

In the excerpted sources, the commercials present the metaphoric transfer in a more dynamic way and it is more difficult to follow the narrative and identify the existing metaphors as the shots follow in quick succession in most of the cases. On the contrary, the print ads show the two domains simultaneously and it is left to the reader to decode the intended information correctly in the way advertising agents have planned and projected it.

In commercials, a number of anticipatory mechanisms should be at play on part of TV audiences as the object of attention would usually appear at the end of the narrative. So, text receivers start making hypotheses and presuppositions about what follows next as is the case with one of Wes Anderson's IKEA ads titled Living Room. The story is constructed in the form of a dialogue:

Mother: Tell me what's wrong.

Daughter: I'm pregnant.

Mother: Oh, my God.

Father: I knew it... I knew it. It's that creepy boyfriend of yours, isn't it? I told you this would happen.

Daughter: Dad, stop.

Mother: So it's my fault now?

Father: Where do you think she got that stuff from, not from me. You smoked pot in college so...

A: So... what do you think?

Mother: I like it. 
Father: Feels good.

Mother: We'll take it.

(The pictorial part of the narrative represents workers carrying the constructions of a living room. There are other customers passing by. There are also some construction drawings with IKEA's name)

IKEA shop unböring (https://www.youtube.com/watch?v=0CCL-vhEtf4)

What is presented is a real life situation in which a family is planning to buy some furniture for their living room, so they are in one of IKEA shops sitting in a model living room, at the same time discussing social issues typical for any family. The narrative is full of dynamism and shots change very quickly as everything normally happens in reality. At first sight the plot of the narrative has nothing in common with the essentials of the advertising object but the way the commercial begins immediately attracts the audience's attention having to do with a topic which is more or less a taboo or at least a concern for every family: the daughter in the family makes a confession to her mother that she is pregnant, which then leads to a quarrel between the girl's parents.

This unexpected beginning of the text has its reasons and they are that recipients would be attracted to the commercial, influenced effectively and stimulated to buy the advertised product no matter what it is. In principle, people like sensations and especially news having negative orientations; they are provoked by them and tempted, if not 'seduced', to avail themselves of the offers. The juxtaposition in this case is achieved with the help of negative emotions, associations and reactions related to the bad news having caused the family scandal. The object of advertising, in this case IKEA living rooms, is presented with the help of the strategy of situating the product in social reality but at a much later stage. The unexpected way of introducing the goods attracts the audience's attention and the copywriter's aim is achieved to the full. Another provocative moment in the commercial has to do with the role of women, which is not the one of the mother and the faithful wife, but of the disobedient daughter, something which brings negative feelings but which is somehow forgotten and replaced by positive ones caused by the final decision made about buying the advertised item: 'I like it. Feels good. We'll take it'. In both presented situations, the dynamism typical for modern societies leads to reaching a solution to the problem. The last reactions, though referring to the furniture, can ambiguously be related to the mentioned issue. The whole text is based on the opposition between bad and good news. The metaphoric transfer is fulfilled with the mixing of entities from two domains as people mentally make the connection between time and space (see Radden 2011).

The complex isotopy directs the addressee towards two referential fields leading to completely contradictory perceptions, i.e. that of the time concept through 
the space dimension metaphor and a certain risk-provoking feeling having to do with both fields, that of pregnancy and of possession of the living room. The play on words in the slogan makes the narrative even more memorable: 'IKEA shop unböring'. It is achieved with the help of the neologism unböring valid only for the respective text. 'Unböring' can also stand for something which is not boring, i.e. interesting, different, provocative even. It is most probably associated with what is ahead of the young woman, the baby (not born yet) and with the ideas implemented in the furniture IKEA makes. The "o" with umlaut reminds one of the origin of the company offering the goods - it is Swedish. It, however, requires previous knowledge about the latter. Otherwise, recipients may think that there is a mistake in the way the word is written. This technique coincides with advertising agents' willingness for the information to fit into the addressees' models of the world to the maximum and it is definitely intended and well thought of. Those people who are interested in IKEA products would most probably be aware of the nationality and origin of the company. The mixing of entities from the two isotopic fields leads to metaphoric transfer of knowledge, related to cultural awareness and experiences exploited in the present advertising discourse. Or, in this case, as Landau has stated, 'metaphoric thinking' has to do with 'mapping two things belonging to superficially different orders of experience' (Landau 2017: 34). Although the two parts belong to completely different schemas, the domains that are used for presenting the information are familiar to target audiences, which supports Kövecses' statement that

Part of the selling power of an advertisement depends on how well chosen the conceptual metaphor is that the picture and/or the words in the advertisement attempt to evoke in people. An appropriately selected metaphor may work wonders in promoting the sale of an item (Kövecses 2010: 65).

This type of metaphor is called hybrid pictorial metaphor (see Forceville 2006) as the two domains have practically nothing in common but we can define it as a contextual metaphor as well as the dialogue takes place in the living room which turns out to be the object of attention at a later stage. 'In contextual metaphor, one term is described or characterized, the other is not, but unambiguously suggested by the pictorial context' (see Tjirakusuma, URL). It can also be termed a multimodal metaphor as the compared entities exist in the non-verbal component but through the verbal one. 'Feels good. We'll take it' can be considered to refer to the situation discussed and to the offer at the same time. The second sentence can stand for both 'take the living room' and 'take the risk'. Multimodal metaphors are defined as those 'whose target and source are each represented exclusively and predominantly in different modes' (Forceville 2006: 384). The way this particular metaphor is presented is very subtle and it may not be conceived as such. It is not that easy to identify the source and the target domain as the first one comes first and then it is gone but the impression it leaves is strong as it is usually the case for bad news to be 
remembered longer rather than the good ones. On the other hand, as humans are curious enough, they will watch the commercial till the end to find out what the advertised item is. Time is, however, presented along two lines with the help of one and the same spatial metaphor: time for the baby to be born and taken care of and time for the living room to be ready, both in the same spatial parameters. The interpretation of the information relies on previous experiences and social practices. The two processes imply positive motions and actions which have to do with spatial orientation metaphors, in this case the direction being up and/ or forward. In most cases, as Landau has stated: "Metaphors help by mapping the target situation onto well-learned schemas borrowed from other domains" (Landau 2017: 18). In the presented commercial the target and the source domain are placed in two different modes which occur consecutively in the nonverbal part of the narrative through "moving images", and yet other concurrent modes as simultaneously with the voice-over, i.e. the dialogue itself, together with it, there is yet a "third channel", "the aural" (see Forceville 2007, URL). The target domain which is the new IKEA living room is shown at a much later stage in the visual mode, towards the end of the commercial. However, the source and the target domain in the pictorial component "rely on a verbal reinforcement to reach the most accurate understanding...; in other words, there is a possible continuum existing between monomodal and multimodal metaphor in commercial advertising as Rodríguez has stated (2016: 113).

Forceville's opinion of multi-medial metaphors as he calls them is that they contribute to "a better understanding of culturally embedded knowledge and beliefs" (see Forceville 2007, URL).

In this particular context, the culture-specific factor of the discussed issues in the first part of the text is valid for most societies and it is oriented to moral values existing in communities anywhere in the world. One of the reasons for the application of this technique is that the company has branches all over the world and it should look for ways of rendering information which can be not only intriguing but also accepted by as many addressees as possible, quite successfully at that. 


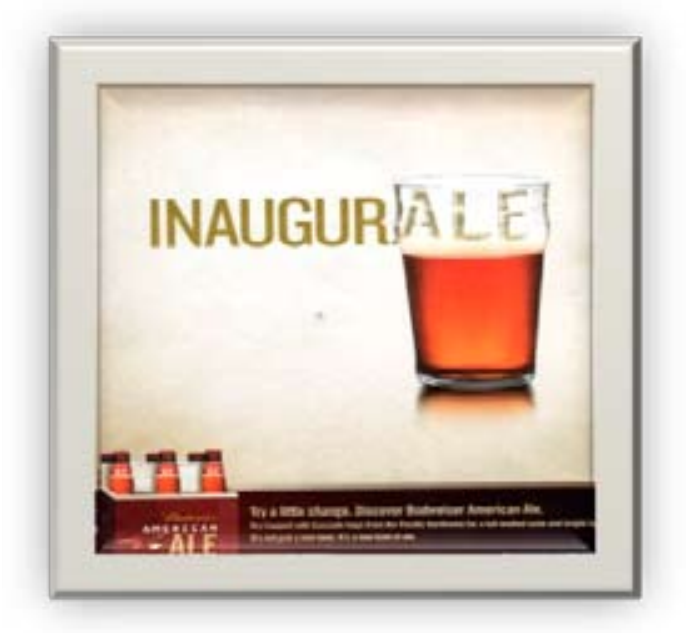

One of the samples from the corpus is a print advertisement about Budweiser American ale in which there is a multimodal metaphoric transfer based on wordplay. The occasionalism INAUGURALE is used and it is valid only for this particular context and time of publishing the ad (January 19, 2009). Part of the source domain is present in the caption in the non-verbal component and it refers to the existing social practices at that time. The target domain is present in the visual mode. Their awareness will definitely satisfy and please the target readership as the latter will be able to associate the use of the newly coined word with the history, politics, culture and social changes of the day in the USA. The date of the promotion of the beer and of the appearance of the ad even precedes the great event. The play on words may not be understood at all and it can hinder and block comprehension or it can be decoded only on a superficial level, i.e. relate INAUGURALE to the official introduction of the new beer ("inaugurate" meaning "to dedicate ceremoniously" + "ale"). The deeper comprehension of the text is connected and coincides with Barak Obama's election and inauguration (January 20, 2009). All people know that he is the first African American who served as president of the United States of America. In this respect, the expression try a little change, or in other words "try something different which may bring a little spice in Americans' life" may come handy as well. They indirectly mention the 'freedom' of choice. This 'freedom' of choice is related to recipients' decision to make a change by trying something different, namely this particular beer. Indirectly, this freedom of choice may also refer to the political event. The latter is just a hint. It is not mentioned anywhere in the text. But the time frame related to the publishing of the ad coincides with all the political and social activities in the USA. The command in the advertisement "Sip. Savor. Repeat." sounds like the famous command used at the beginning of a race "Ready. Steady. Go". In this case, we may say, that it is even a rat race on 
two levels and in the two domains - the source and the target. The rat race will be in politics as well as with the other brands of beer. Its simplicity based on a familiar association is the right choice, because it is easily memorised and sticks to mind. The text goes in the following way:

Try a little change. Discover Budweiser American Ale... It's not just a new kind of beer. It's a new kind of ale.

Sip. Savor. Repeat. Responsibility matters. (http://www.eatmedaily.com/2009/01/ budweiser-exploits-inauguration-with-inaugurale-advertisement/)

The type of metaphor in the ad is pictorial with two components, as Forceville (2006) has put it. In principle, there are metaphors which exist on several levels at one and the same time, and Švažiene calls them "metaphorical blends" (Švažienè 2010: 112). Others refer to this type of metaphor as integrated metaphor. The abovementioned example is an instance of such a metaphor irrespective of its naming; however, the idea is the same. The two domains are blended into one or integrated and their interpretation will be successful if addressees or text recipients get the point correctly and relate the idea to the current situation. We may even consider the use of this type of metaphoric transfer a kind of ideology for those who can get the initial plan of advertising agents.

\section{Results and Key Findings}

The analysis confirmed the fact that there are a couple of factors that play an important role in decoding metaphoric transfer in advertising discourse, some of which social-cultural (see Gibbs, Cameron 2008) and cognitive (see Steen 1999). The way communication and manipulation are achieved through metaphors in this type of text can be different in different cultures because of our way of thinking, our previous knowledge and experiences as well as our knowledge about the world. Even in cases in which we belong to the same culture, social group and respective community we may not be able to decode the ads correctly as we may lack previous knowledge and experience or we may not be able to make the necessary connections between the presented entities and the entities which are just prompted by a number of extra textual factors on the unconscious or the subconscious level.

The idea of understanding metaphors in ads is supposed to be something related to pleasure rather than to something leading to either misunderstanding them, difficulties of decoding them or not understanding them at all. Either of these would result in negative attitudes towards the advertised item.

The findings show that metaphoric transfer in the analysed corpus is based on cultural, political, historical aspects and existing social practices in terms of word play occasionalisms (neologisms); situations, which seem irrelevant to the advertised scheme, even contradicting target audience expectations about the 
advertised product. At times, the metaphoric transfer remains on the superficial and more literal level as there might be text recipients who are not capable of getting the deeper intentionality of advertising agents.

The results prove the fact that the use of multimodal metaphors, especially in the non-verbal component, is much more tantalising as it triggers more emotions and feelings than the mere representation of the advertised items. In commercials, there is a third channel (the aural one) which helps in the comprehension of the metaphoric transfer and yet it is more difficult to grasp the idea behind the narrative as motions are quite dynamic. In printed ads, text receivers have more time to think over the transmitted messages and the metaphors used but if these people do not have the necessary cultural and social background as well as previous experiences related to the respective story, they can miss the intended meaning behind this metaphoric transfer. If they realise the fact that there is something they have not understood, they will give up decoding the information and they may even become indifferent and/or acquire a negative attitude toward the advertised item.

\section{Conclusion}

In general, people accept the world in a different way which means that in a number of cases one and the same metaphor will be interpreted differently. However, this is not the most important thing in advertising discourse. What matters is the fulfillment of the pleasure principle (see Freud 1985) while decoding metaphors in these types of text which will then be transferred to the product when it is bought.

\section{Implications}

The implications for future research in this field can be to use informants and try out the comprehension of metaphors on informants who can be students, professionals in the field as well as non-professionals (people chosen at random) as these types of text are directed to everybody, their aim being successful manipulation leading to the expected purchase.

\section{References:}

Donoghue 2014: Donoghue E. Metaphor. Cambridge, MA: Harvard University Press.

Downing, Locke 1992: Downing A., P. Locke. University Course in Englsih Grammar. New York: Prentice Hall. New York English Language Teaching Series.

Emanatian 1995: Emanatian M. Metaphor and the Expression of Emotion: The Value of Cross-Cultural Perspectives. - Metaphor and Symbolic Activity. vol. 10. 1995. Issue 3, 163-182. 
Fauconnier, Turner 2002: Fauconnier G., M. Turner. The Way We Think: Conceptual Blending and the Mind's Hidden Complexities. New York: Basic Books.

Forceville 2006: Forceville C. Pictorial Metaphor in Advertising. London and New York: Routledge.

Forceville 2007, URL: Forceville, C. A Course in Pictorial and Multimodal Metaphor. $<$ https://semioticon.com/sio/courses/pictorial-multimodal-metaphor/>. [Accessed 12 June 2017]

Forceville, Urios-Aparisi 2009: Forceville C., E. Urios-Aparisi (eds.) Multimodal Metaphor. Berlin: Mouton de Gruyter.

Freud 1985: Freud S. Art and Literature. vol. 14. Dickinson A. (ed.). London: Penguin.

Gibbs, Cameron 2008: Gibbs R. W., L. Cameron. The Social Cognitive Dynamics of Metaphor Performance. - Cognitive Systems Research. 9(1-2), 64-75.

Goatly 2007: Goatly A. Washing the Brain: Metaphor and Hidden Ideology. Amsterdam: Benjamins.

Goatly 2011: Goatly A. The Language of Metaphors. 2nd ed. New York: Routledge.

Kövecses 2000: Kövecses Z. Metaphor and Emotion: Language, Culture, and Body in Human Feeling. Cambridge: Cambridge University Press.

Kövecses 2005: Kövecses Z. Metaphor in Culture: Universality and Variation. New York: Cambridge University Press.

Kövecses 2005: Kövecses Z. Metaphor, Culture, and Discourse: The Pressure of Coherence. - In: Musolff A., J. Zinken (eds). Metaphor and Discourse. New York: Palgrave Macmillan. 11-24.

Kövecses 2010: Kövecses Z. Metaphor: A Practical Introduction. New York: Oxford University Press.

Kövecses 2015: Kövecses Z. Where Metaphors Come From: Reconsidering Context in Metaphor. New York: Oxford University Press.

Molhova 1976: Molhova J. Outlines of English Lexicology. Sofia: Naouka i izkoustvo.

Musolff, Zinken 2009: Musolff A., J. Zinken. Metaphor and Discourse. New York: Palgrave Macmillan.

Lakoff, Johnson 1980: Lakoff G., M. Johnson. Metaphors We Live By. Chicago: The University of Chicago Press.

Landau 2017: Landau M. J. Conceptual Metaphor in Social Psychology: The Poetics of Everyday Life. New York and London: Routledge. Taylor \& Francis Group.

Radden 2011: Radden G. Spatial Time in the West and the East. - In: Brdar M., Omazic M., Takac V., Gradecak-Erdeljic T., G. Buljan (eds.). Space and Time in Language. Frankfurt: Peter Lang.

Rodríguez 2016: Rodríguez M. I. M. Analysing Metaphors in Commercial Advertising. Verbeia Número. 1, 107-125.

Schnall 2014: Schnall S. Are There Basic Metaphors? - In: Landau M. J., Robinson M., B. Meier (eds.). The Power of Metaphor: Examining Its Influence on Social Life. Washington, DC: APA Press. 225-248.

Steen 1999: Steen G. J. From Linguistic to Conceptual Metaphor in Five Steps. - In: Gibbs R. W. JR., G. J. Steen (eds.). Metaphor in Cognitive Linguistics. Amsterdam: John Benjamins. 57-77. 
Švažienė 2010: Švažienė L. The Persuasive Effect of Metaphor in Advertising. - Jaųnu̧jų Moksli’ninkų. Darbai. Nr. 2 (27). 2010. 111-115.

Tjirakusuma, URL: Tjirakusuma, N. I. <http://repository.petra.ac.id/16647/1/Publikasi1 84 001_1519.pdf.>

\section{Excerpted sources:}

https://www.youtube.com/watch?v=0CCL-vhEtf4. Published August 15, 2009. [Accessed 12 June 2017]

http://www.eatmedaily.com/2009/01/budweiser-exploits-inauguration-with-inauguraleadvertisement/. Published January, 19, 2009. [Accessed 12 June 2017]. 